\title{
AFTER THE CROP: THE IMPACT OF DOWNSIZING ON PHOTOJOURNALISM QUALITY
}

\author{
Phoebe Sexton \\ Dr. Keith Greenwood, Thesis Supervisor
}

\begin{abstract}
Journalism's role in society is to disseminate information. The quality of this information is important for readers and for the long-term viability of the newspaper. Layoffs could compromise the ability to produce quality content in the whole newsroom and also in photojournalism, an under-researched and important sector of the news industry. The purpose of this study is to determine whether the quality of photographic coverage has been affected by layoffs in newspaper photography departments. Using two samples from before and after a period of heavy layoffs, a content analysis of images $(\mathrm{N}=1,288)$ was conducted to examine the quality of photographic coverage at four midsized regional newspapers. Using a six-category scale modified from Lacy and Fico, images were evaluated for quantity, size, source (byline), location, average per page and average per story. Using the quantitative data, in-depth interviews were conducted with each newspaper's visual manager to provide context for the content analysis. Results were mixed, showing improvement in some areas and drastic decline in others, particularly in numbers of news pictures. Photography editors have implemented several innovations and improvements in efficiency, but are still hindered by strained resources.
\end{abstract}

